\title{
Biodiesel and Product Potential of Microalgae Dunaliella Salina By NMR Techniques
}

\author{
Sarpal A S ${ }^{1}$, Claudia MLL Teixeira ${ }^{2}$, Sabrina Mesquita ${ }^{2}$, Ingrid CR Costa ${ }^{1}$ and Paulo RMS ${ }^{1}$ \\ ${ }^{1}$ Department of Metrology, National Institute of Metrology, Quality and Technology, Brazil \\ ${ }^{2}$ Department of Metrology, National Institute of Technology, Brazil
}

Submission: May 12, 2018; Published: September 21, 2018

*Corresponding author: Sarpal A S, Department of Metrology, National Institute of Metrology, Quality and Technology, Brazil,

Email: sarpal.as2@gmail.com

\begin{abstract}
Systematic studies have been conducted to characterize both $\beta$-carotene and Tri-Glycerides (TG) present in the solvent extracts of biomass of microalgae Dunaliella Salina by Nuclear Magnetic Resonance (1D and 2D NMR) techniques. The NMR spectral interpretation results have shown that besides TriGlycerides (TG), which are important components of biodiesel, the $\beta$-carotene and its isomer astaxanthin could easily be identified in a complex mixture. The TG are comprised of both unsaturated (C18:1, C18:2; n-3 C18:3, C22:6) and saturated (C16:0, C18:0) fatty acids as revealed by $1 \mathrm{H}$ NMR and GC-MS analyses of extracts. The quality parameters such as n-3 PUFA and iodine value have been determined from the integral intensities of the respective functional groups corresponding to these parameters.
\end{abstract}

Keywords: $\beta$-carotene; Dunaliella salina; Tri-Glycerides; Microalgae, NMR (ID\&2D) techniques, GC-MS, Biodiesel, Neochloris; Botryococcus; Scenedesmus; Dunaliella; Tetraselmes; productivity; pigments; vitamins ; proteins; algal oil; iodine; Dunaliellaceae; plastids; Human health; molecules; Haematococcus pluvialis;

Abbreviations: TG: Tri-Glycerides; FFA: Free Fatty Acids; PUFA: polyunsaturated Fatty Acids; FAME: Fatty Acid Methyl Ester; DHA: Docosa Hexaenoic Acid;

\section{Introduction}

Biodiesel from microalgae seems to be the only renewable biofuel that has the potential to completely replace the petroleum-derived transport fuels. Various species of microalgae are potential candidates for $\mathrm{CO}_{2}$ mitigation and products such as biodiesel, n-3 $\omega$ PUFAs (C18:3, C20:5, C22:6) etc. The oil rich and high productivity microalgae genera such as Neochloris, Botryococcus, Scenedesmus, Dunaliella, Tetraselmis and Chlorella have been investigated for their biodiesel and product potential [1-12]. The community analyses including taxonomy and pigment analyses of a large number of microalgae species have been systematically described by Serive and co-workers [13]. Biodiesel potential of oleaginous microalgae biomass is associated with the biomass productivity, mainly content and quality of neutral lipids (tri-glycerides,TGs; Free Fatty Acids, FFA), achieved during cultivation process. Microalgae are also the major food source for many aquatic organisms, which are highly recommended for human consumption due to the presence of polyunsaturated Fatty Acids (PUFA) and essential nutrients in their biomasses $[1,4,11]$. Microalgae are cultivated in sea or fresh water but grow very well in waste waters by utilizing very efficiently $\mathrm{P}$ and $\mathrm{N}$ of these media [14-20]. These sources have been found to be very convenient and effective for biodiesel and value-added products such as PUFA, pigments, vitamins and proteins $[1,4,5,6,16]$.

The composition and nature of neutral lipids and their fatty acids profile, particularly unsaturated including PUFA, are dependent on the cultivation parameters such as temperature, composition of medium, types of feed, light intensity etc. [4,6,1720]. The fatty acids profile of algal oil is comprised of C12-C24 saturated and unsaturated fatty acids, which is more or less similar to those present in vegetable and fish oils $[5,6,8,16]$. TGs from microalgae biomasses are converted into Fatty Acid Methyl Ester (FAME) (biodiesel) by usual chemical hydrolysis followed by esterification or enzymatic transesterification [19]. Biodiesel from microalgae can be used as B100 (neat biodiesel) or blended with conventional diesel at a level of 5\% (B5) or 10\% (B10) or $20 \%$ (B20). Most of microalgae biomasses are rich sources of $\mathrm{n}-3 \omega 3$ and n-6 $\omega 6$ fatty acids including C18:3 (Linolenic), C20:5 (Eicosatetraenoic Acid, EPA) and C22:6 (Docosa Hexaenoic Acid, DHA) as indicated by very high iodine value of 90 to 140 of solvent extracts $[1,5,6,8,16]$. Thus, biodiesel from algal oil is not an appropriate fuel for direct combustion in sensitive engines due to its high content of PUFAs $(10-40 \% \mathrm{w} / \mathrm{w})[1,4]$. However, extraction of PUFA by solvent extraction methods or 
hydrotreating/hydrocracking of algal oil are considered useful options for making biodiesel with oxidation stability similar to those inherited by biodiesel from oil crops [21].

Dunaliella is a genus of the algae family Dunaliellaceae. Dunaliella sp., which is motile, unicellular, and 9-11 $\mu \mathrm{m}$ size green algae are common in marine waters. Dunaliella tertiolecta is reported to have oil yield of about $37 \%$ (organic basis). $D$. tertiolecta is a fast-growing strain and that means it has a high CO2 sequestration rate as well [14, 22-28]. The influence of light source, light intensity, $\mathrm{CO} 2$ concentration, and photoperiod on the growth of $D$. tertiolecta was studied. The effects of these environmental parameters on the lipid content and fatty acid composition of $D$. tertiolecta have been investigated. Methyl linolenate and methyl palmitate were found to be the major components of FAME produced from D. tertiolecta oil. Thus, derived oils are a suitable feedstock for biofuel production $[22,23]$.

The best-known species is extremely salt tolerant. This species under stress conditions such as high light intensity or nutrient starvation, overproduces $\beta$-carotene, which is accumulated in the plastids in newly formed triacylglycerol droplets. Dunaliella salina is the richest natural source of the carotenoid, $\beta$-carotene. The halophilic species of Dunaliella also accumulate very high concentrations of glycerol. Dunaliella salina was first proposed as a commercial source of $\beta$-carotene and later as a source of glycerol. $\beta$-carotene from Dunaliella is now being produced on a commercial scale in Australia, USA and Israel. In Dunaliella salina and Dunaliella parva the chloroplast accumulates large quantities of $\beta$-carotene (as droplets) so that the cells appear orange-red rather than green, especially in stress conditions [22-24]. When exposed to stress conditions such as high light intensity or nutrient starvation, two stereoisomers of $\beta$-carotene, all 9-trans and 9-cis $\beta$-carotene, accumulated, reaching up to $14 \%$ of the cell's dry weight, with the pigment being deposited into plastid. Carotenoids have several proven benefits to human health being that some of them exhibit pro vitamin $A$ activity, and $\beta$-carotene is the only molecule capable of generating two molecules of retinol (vitamin A) [29,30]. $\beta$-carotene has the formula of $\mathrm{C} 40 \mathrm{H} 56$, a molecular weight of 536.9 , eleven conjugated double bonds and a typical violet-red crystalline color and it forms a solution in oil. $\beta$-carotene shows an absorption maximum in petroleum ether at $453 \mathrm{~nm}$ and 481 $\mathrm{nm}$.

Astaxanthin is a carotenoid widely used in salmonid and crustacean aquaculture to provide the pink color characteristic of that species. Additionally, astaxanthin also plays a key role as an intermediary in reproductive processes. Synthetic astaxanthin dominates the world market but production of natural sources of the pigment is generating interest. Common sources of natural astaxanthin are the green algae Haematococcus pluvialis, the red yeast, Phaffia rhodozyma, as well as crustacean byproducts. Astaxanthin possesses an unusual antioxidant activity which has caused a surge in the nutraceutical market for the encapsulated product. Also, health benefits such as cardiovascular disease prevention, immune system boosting, bioactivity against Helycobacter pylori, and cataract prevention, have been associated with astaxanthin consumption [25-28].

The analytical techniques used for compositional analyses of microalgae biomasses, particularly NMR and GC-MS techniques have been described well in our previous work $[1,4,5]$. NMR techniques are well suited for the compositional characterization, quantitative analyses of lipids, fats (glycerides, free fatty acids) and fatty acid composition including PUFAs [1-6, 31,32]. In the present investigation, the $1 \mathrm{H}$ NMR spectroscopic techniques including 2D NMR have been used to characterize $\beta$-carotene in the complex mixture of fats and fatty acids.

\section{Methods and Materials}

\section{Cultivation of Dunaliella Salina}

Cultivation was carried out in triplicate being initiated with $2 \times 104$ cells/mL in culture medium described by Shaish, Ben-Amotz and Avron, containing $\mathrm{NaCl}$ at $1 \mathrm{M}$ and $\mathrm{pH}$ 8.00. The cultivation was conducted in Erlenmeyer flasks with $300 \mathrm{~mL}$ of culture, which were under illumination promoted by fluorescent lamps $(20 \mathrm{~W})$, at $200 \mu$ moles of photons. m-2. s-1 irradiance, at orbital agitation of $180 \mathrm{rpm}$ and temperature of $25 \pm 2{ }^{\circ} \mathrm{C}$. Daily, aliquots were withdrawn for the determination of cellular growth. When the cells reached the stationary phase of growth, the cultivation was finished, and all the three cultures were mixed, in order to obtain only one culture. The resultant culture was centrifuged at $3000 \mathrm{rpm}$, for 10 minutes, at $15^{\circ} \mathrm{C}$ (Centrifuge Rotixa $50 \mathrm{~S}$, Hettich). The pellet was re-suspended in a minimum amount of the same medium in which the cells were grown, frozen and subjected to lyophilization.

\section{Extraction strategy}

The cultivated dried biomass was found to contain sufficient amount of salt. Therefore, in order to remove the salt, the biomass was extracted in $\mathrm{CHCl} 3$ in a ultrasonic water bath for one hour at room temperature. The solution was filtered, and solvent was completely evaporated to get the dried extract. This extract was designated as $\mathrm{CHCl} 3$ extract (NMR spectra 2, lower part). In order pre-concentrate the carotene-based components and remove impurities other than tri-glycerides, $\mathrm{CHCl} 3$ extract was dissolved in methanol and chloroform mixture (1:1) and extracted in a separating funnel. The lower layer $\mathrm{CHCl} 3$ was separated and evaporated to dryness. This extract was designated as purified chloroform extract (NMR spectra 3). The upper methanol layer was also evaporated to dryness and was designated as $\mathrm{MeOH}$ extract.

\section{NMR recordings}

The NMR recordings of the $\mathrm{CDCl} 3$ solutions of $\mathrm{CHCl} 3$, and $\mathrm{MeOH}$ and purified $\mathrm{CHCl} 3$ extracts of Dunaliella salina biomass; 
soya oil; and $\mathrm{CHCl} 3$ and cyclohexane extracts of Scenedesmus Dimorph have been conducted as per the procedure and parameters discussed in our previous work [1-6]. The acquisition and processing parameters for 2D TOCSY NMR are explained in the reference 4 .

\section{Transesterification of $\mathrm{CHCl} 3$ and purified $\mathrm{CHCl} 3$ extracts for FAMEs}

These extracts were converted into FAMEs by adopting the usual methanol- $\mathrm{KOH}$ hydrolysis procedure as reported previously $[1,4]$.

\section{Results}

\section{GC-MS analyses}

The GC-MS analyses of the $\mathrm{CHCl} 3$ extract have shown the presence of mainly C16:0 (26.8\%), C16:1 (4.8\%), C20:4 (5.6), C18:0 (3.1\%), C18:1 (23.7\%), C18:2 (13.3\%), C18:3 (15.2\%) and others including C22:6 (7.5\%) fatty acids. The results are in weight percentages.

\section{Composition of solvent extracts of Dunaliella salina by NMR}

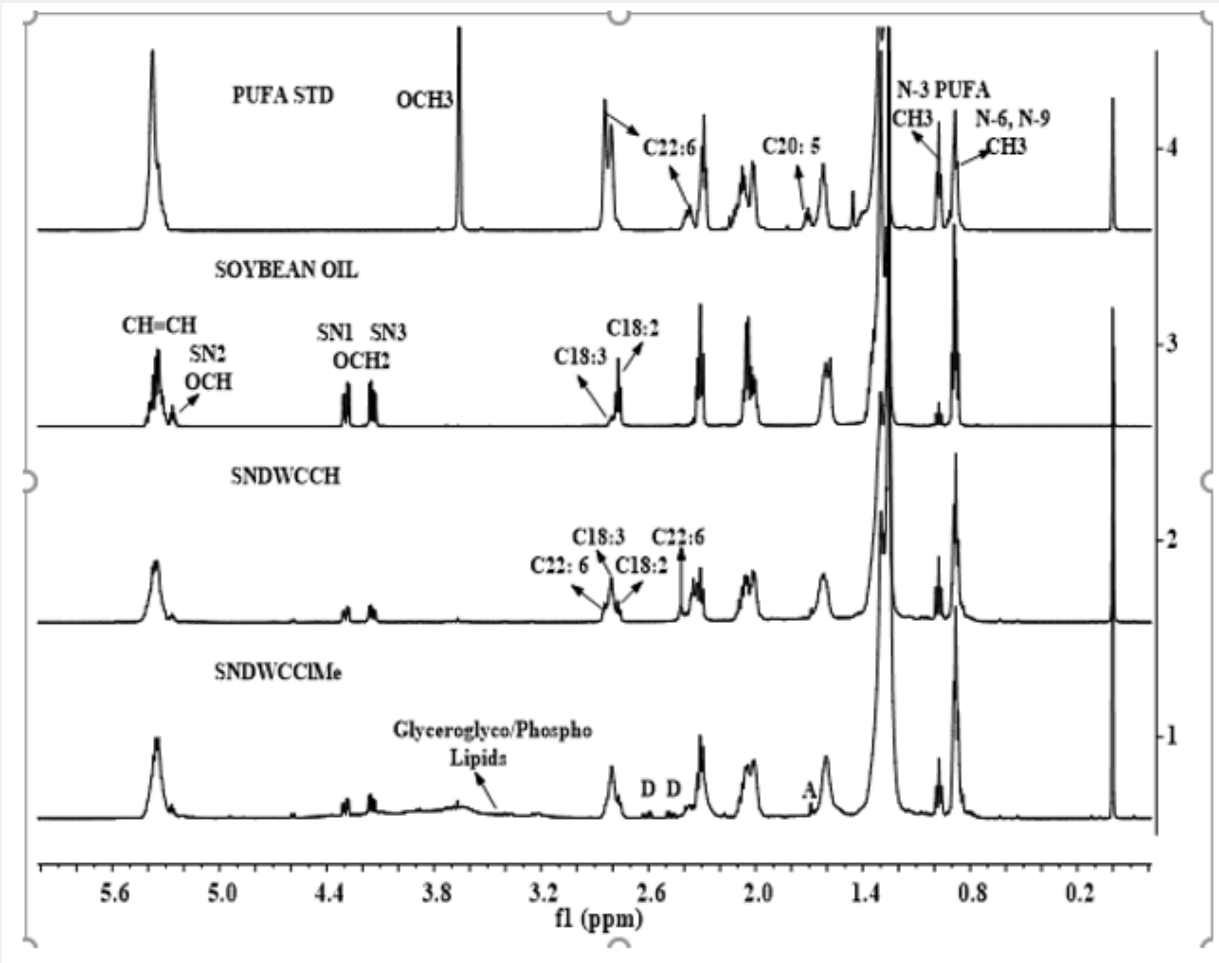

Figure 1: $500 \mathrm{MHz}$ 1H NMR spectra of algal extracts (cyclohexane, $\mathrm{CH} ; \mathrm{CHCl} 3$ ) of microalgae Scendesmus Dimorph in media WC media (SNDWC), soybean and PUFA standard, D= Epoxy ester.

The $1 \mathrm{H}$ NMR spectrum of the chloroform extract of the Dunaliella salina biomass as shown in the Figure 1 has been observed to be quite complicated as signals due to both $\beta$-carotene and triglycerides are overlapped. This is particularly in the region of 0.5 to $3.0 \mathrm{ppm}$, where $\mathrm{CH} 3$ signals of unsaturated chains of $\beta$-carotene and n-3 PUFA are overlapped, thus makes it difficult to assign the signals corresponding to each other. In order to distinguish the signals due to tri-glycerides and $\beta$-carotene in the $\mathrm{CHCl} 3$ extract of a microalgae biomass, the $1 \mathrm{H}$ NMR spectra of $\mathrm{CHCl} 3(\mathrm{CHL})$ and cyclohexane $(\mathrm{CH})$ extracts of the microalgae Scenedesmus biomass were recorded and presented in the Figure 1 [4]. This was considered for spectral comparison and demarcation of signals due to carotene and tri-glycerides in a representative spectrum of a microalgae containing only tri-glycerides. The characteristic signals due to ester groups (OCH2) of glycerol back bone, and functional groups of long chain unsaturated and saturated fatty acid chain such as $\mathrm{CH}=\mathrm{CH}$, $\mathrm{CH} 2-\mathrm{CH}=\mathrm{CH}-, \mathrm{CH}=\mathrm{CH}-(\mathrm{CH} 2)-\mathrm{CH}==\mathrm{CH}-$, terminal $\mathrm{CH} 3 \mathrm{~s}$ and long alkyl chain (CH2) $n$ are marked for better understanding of the spectral features.

The spectral features of the algal extract resemble with those of soya oil and PUFA standard as shown in the same Figure 1. The characteristic signals due to PUFAs were found to observed at $0.98 \mathrm{ppm}(\mathrm{CH} 3)$ and $2.81 \mathrm{ppm}(-\mathrm{CH}=\mathrm{CH}-(\mathrm{CH} 2) 2-)$ for $\mathrm{C} 18: 3$; and at $0.98 \mathrm{ppm}(\mathrm{CH} 3)$ and $2.84 \mathrm{ppm}(\mathrm{CH}=\mathrm{CH}-(\mathrm{CH} 2) 5-)$ for $\mathrm{C} 22: 6$ as indicated in the Figure 1. The signals corresponding to functional groups of tri-glycerides are compiled in the (Table 1). 
Table 1: $1 \mathrm{H}$ characteristic chemical shift regions of different components of algal extracts.

\begin{tabular}{|c|c|c|c|c|c|c|c|c|c|c|}
\hline Quality P & TG ITG & FFA IFFA & C18:1 & C18:2 & C18:3 n-3 ILA & C20:5 & C22:6 & PUFA IPF & UFA IUFA & IV IUS \\
\hline $\begin{array}{c}\text { 1HNMR } \\
\text { ppm }\end{array}$ & (4. 25 & $2.32-2.38$ & 2 & 2.77 & $\begin{array}{c}2.8 \\
10.98(0.925- \\
1.02)\end{array}$ & 1.68 & $\begin{array}{c}2.39- \\
2.40(2.37- \\
2.42)\end{array}$ & $\begin{array}{c}0.98 \\
(0.925- \\
1.02)\end{array}$ & $1.86-2.18$ & $5.05-5.65$ \\
\hline
\end{tabular}

$\mathrm{P}=$ parameter, $\mathrm{TG}=$ Triglycerides, FFA=Free Fatty Acid, PUFA=PolyUnsaturated Fatty Acids, UFA total Unsaturated Fatty Acids, IV=lodine Value the values in the bracket are the chemical shift regions used for integrated intensities of a particular quality parameter, ITG, IFFA etc. are the integrated intensities of TG, FFA etc parameters in the respective chemical shift regions.

Microalgae Dunaliella is a rich source of $\beta$-carotene and astaxanthin, which are essential food ingredient for human consumptions [22-30]. $\beta$-Carotene is a precursor of the biosyntheses of astaxanthin. Carrots, sweet potatoes, winter squash, dark green leafy vegetables, spinach and fruits like cantaloupe and apricot are sources enriched with $\beta$-Carotene. $\beta$-carotene is a carotenoid, one of a group of plant pigments known to have antioxidant and other effects $[29,30]$. This is a substance in plants that's quickly converted into vitamin A. A number of studies show that people who eat lots of fruits and vegetables that are rich in $\beta$-carotene and other vitamins and minerals have a lower risk of some cancers and heart disease. However, so far studies have not found that beta-carotene supplements have the same health benefits as foods. $\beta$-carotene supplements may help people with specific health problems. Supplements might be used in someone with a clear vitamin A deficiency. They also might help those with the genetic condition

\section{Erythropoietin Protoporphyria (EPP) [29].}

The IH NMR spectral features of $\mathrm{CHCl} 3$ extract of microalgae Dunaliella as given in Figures 2 are matching with the spectral features of standards of $\beta$-carotene and astaxanthin as described in the literature. The chemical structures are described in Figure 3. The characteristic signals due to functional groups of $\beta$-carotene (BC) and astaxanthin (AX) are marked in the same Figures 2 and 3. Although the signals due to each are more or less overlapped, these can be distinguished in the regions of protons of polyene $(\mathrm{CH}=\mathrm{C}-\mathrm{CH} 3) \mathrm{n}$ at $6-6.8 \mathrm{ppm}$, vinyl $\mathrm{CH} 3$ of chain at $2.0 \mathrm{ppm}$ (doublet), - $\mathrm{CH} 2$ - of cyclic ring at $1.5 \mathrm{ppm}$ and iso dimethyl attached to the ring at $1.0 \mathrm{ppm}$. For the purpose of their identification and comparison, these groups are well marked in the Figure 3. The relative intensities of signals at $2.0 \mathrm{ppm}$ and 6-6.8 ppm, indicate that $\mathrm{BC}$ is present at higher concentration compared to AX.

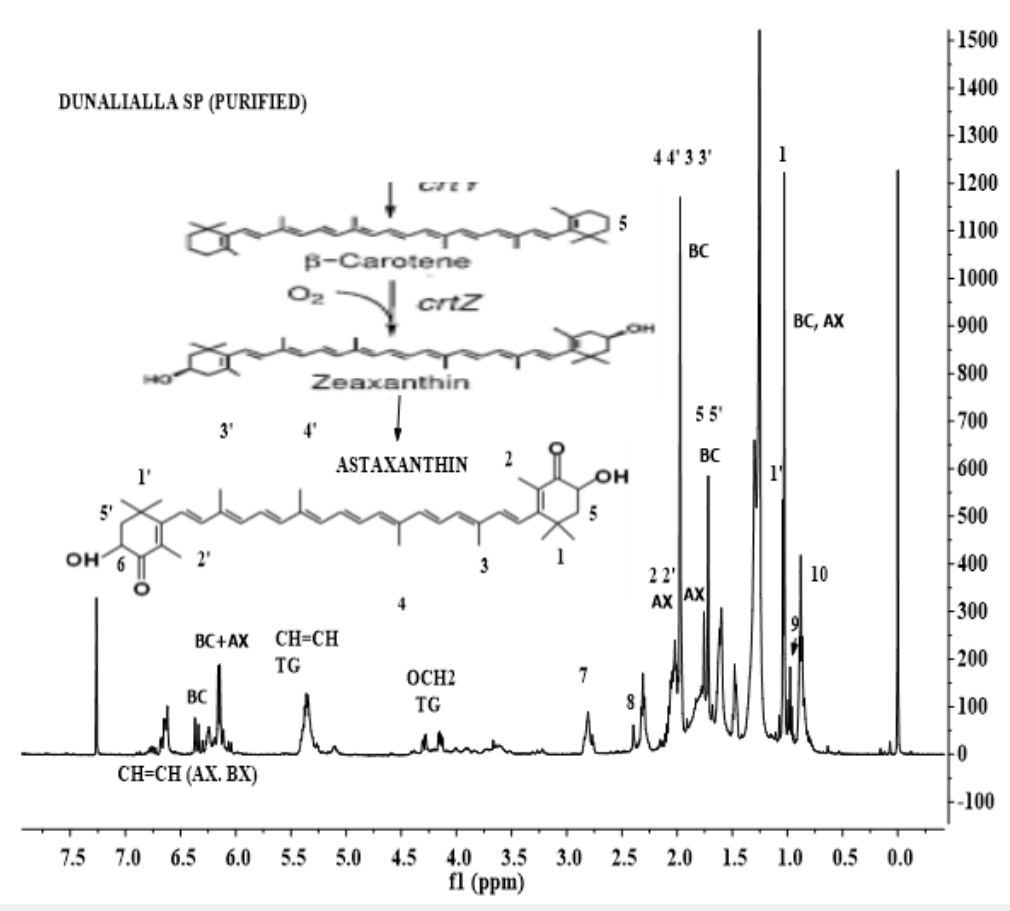

Figure 3: $500 \mathrm{MHz}$ 1H NMR Spectrum of purified CHCL3 extract of microalgae Dunaliella salina. Inset: The chemical structures of BetaCarotene (BC), Zeaxanthin and Astaxanthin (AX) with assignments of functional groups. TG=trglycerides; 7= C18:2, C18:3; 8=C22:6; 9=PUFA CH3; $10=\mathrm{CH} 3$ of C18:1, C18:2, C:N (C14-18)=0. 
Besides the presence of signals due to $\mathrm{BC}$ and $\mathrm{AX}$, the signals characteristics of Triglycerides (TG) and their fatty acid chains, (C18: $\mathrm{N}=0-3$ ) and $\mathrm{C} 22: 6$, are clearly visible in the spectrum (Figure 2). The appearance of intense signals due to terminal CH3s of C18:3 and C22:6 fatty acid chain at 0.98 ppm, 2.81-2.85 ppm and $2.39 \mathrm{ppm}$ are indicative of their presence in quite higher concentration compared to signals due to C18:2 and C18:1 (2.77 ppm and $0.88 \mathrm{ppm}$ ). The weak intensity signals in the regions of 3-4.0 ppm are due to protons of glycerolglyco lipids [4].

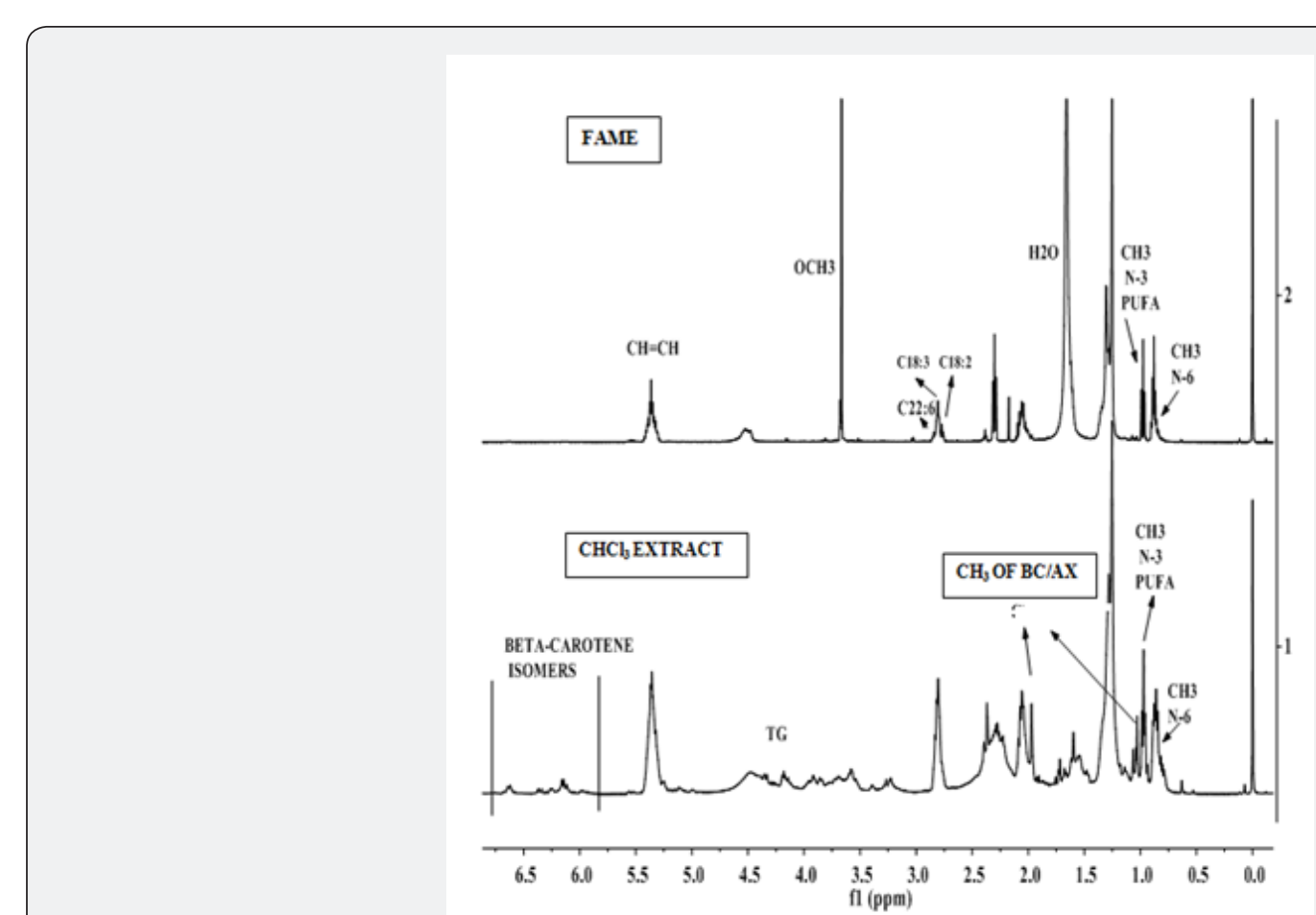

Figure 2: $500 \mathrm{MHz} 1 \mathrm{H}$ NMR spectra of $\mathrm{CHCl} 3$ extract (bottom) and FAME (top) of Dunaliella salina biomass. TG=triglycerides, PUFA=polyunsaturated fatty acid. $B C=\beta$-carotene, $A X=$ astaxanthin.

\section{Discussion}

The $1 \mathrm{H}$ NMR spectrum of $\mathrm{CHCl} 3$ extract of biomass Dunaliella salina given in the Figure 2 depicts signals due to $\beta$-carotene, astaxanthin and triglycerides. Although, signals due to carotenes and glycerides are overlapping, these components could easily be identified and characterized from their characteristics signals, namely OCH2 (4.04-4.4 ppm), $\mathrm{CH}=\mathrm{CH}$ (5.1-5.7 ppm), ( $-\mathrm{CH}=\mathrm{CH}-$ (CH2)2-) (2.6-2.88 ppm) and PUFA n-3 CH3 (0.98 ppm) for TG, and $(\mathrm{CH}=\mathrm{C}-\mathrm{CH} 3) \mathrm{n}(6-6.8 \mathrm{ppm})$, vinyl $\mathrm{CH} 3$ of chain at $2.0 \mathrm{ppm}$ (doublet), - $\mathrm{CH} 2-$ of cyclic ring at $1.5 \mathrm{ppm}$ and iso dimethy for $\mathrm{AX}$ and $\mathrm{BC}$ components. The signals due to $\mathrm{TG}$ are quite intense compared to those of $\mathrm{AX}$ and $\mathrm{BC}$ indicating their relative amount in the extract. In order to further substantiate these results, the $\mathrm{CHCl} 3$ extract was further purified in order to pre-concentrate $\mathrm{AX}$ and $\mathrm{BC}$, which was designated as purified $\mathrm{CHCl} 3$ extract and discussed in the section of materials and methods. The $1 \mathrm{H}$ NMR spectrum of the purified $\mathrm{CHCl} 3$ extract as shown in the Figure 3 demonstrate similar characteristic signals due to $\mathrm{AX}$ and $\mathrm{BC}$, but with quite higher intensities compared to signals appeared for TG.

This is particularly for signals corresponding to polyene $(\mathrm{CH}=\mathrm{CCH} 3) \mathrm{n}$ and iso dimethyls appearing at 6-6.8 ppm, 2.0 ppm, $1.7 \mathrm{ppm}$ and $1.0 \mathrm{ppm}$ for $\mathrm{AX}$ and $\mathrm{BC}$. The $1 \mathrm{H}$ NMR spectra of
$\mathrm{MeOH}$ extract, which was in a very small amount, mostly shows signals due to glyceroglyco lipids and FAMEs (spectra not given). FAMEs signals might have been due to either naturally occurring FAMEs or due to transesterification of fats in the presence of methanol and ultrasonic extraction. However, these results need to be verified by conducting systematic studies involving ultrasonic extraction.

\section{D Total correlated spectroscopy (TOCSY) NMR analyses of extract}

2D TOCSY (Total Correlation Spectroscopy) NMR plot creates $1 \mathrm{H}-1 \mathrm{H}$ correlations between all protons within a given spin system for adjacent (vicinal) and distant (geminal) protons. Correlations are also seen between distant protons in contrast to COSY spectrum where correlations are observed between adjacent protons. This experiment is very useful in identification of components in a mixture depicting overlapped signals in ID $1 \mathrm{H}$ spectral analyses as explained previously [4]. The 2D TOCSY NMR contour plot of the purified CHCl3 extract as shown in the Figure 4 clearly shows correlation among protons of functional groups of triglycerides, particularly between protons of ester (OCH2) group at 4.05-4.35 ppm (marked TG), and between unsaturated protons $(\mathrm{CH}=\mathrm{CH})$ (marked lines a, a; and b). Similarly, the clear and sharp connectivity among 
protons of functional groups of long alkyl fatty chains such as $\mathrm{CH}=\mathrm{CH}(5.2-5.6 \mathrm{ppm}), \mathrm{CH} 2 \mathrm{C}=\mathrm{O}(2.05-2.40 \mathrm{ppm}), \mathrm{CH}=\mathrm{CH}-\mathrm{CH} 2$ (2.4-5-2.9 ppm), n-3 CH3 of PUFAs (C18:3, C22:6) (0.98 ppm) and ( $\mathrm{CH} 2) \mathrm{n}$ (1.1-1.4 ppm) are observed. Though there are clear demonstration of connectivity observed among the protons of polyene (6-6.8 ppm) of $\mathrm{AX}$ and $\mathrm{BC}$, no correlations among the protons of $\beta$-carotene (BC) or astaxanthin, and Triglcerides (TG) were observed as indicated in the 2D plot. Also, no correlations, vicinal or geminal, have been observed for dimetyl and polyene CH3. These critical interpretations offered by 2D NMR analyses confirmed the results obtained by ID 1 H NMR analyses (Figure 2 \&3), particularly for the presence of $\mathrm{AX}$ and $\mathrm{BC}$.

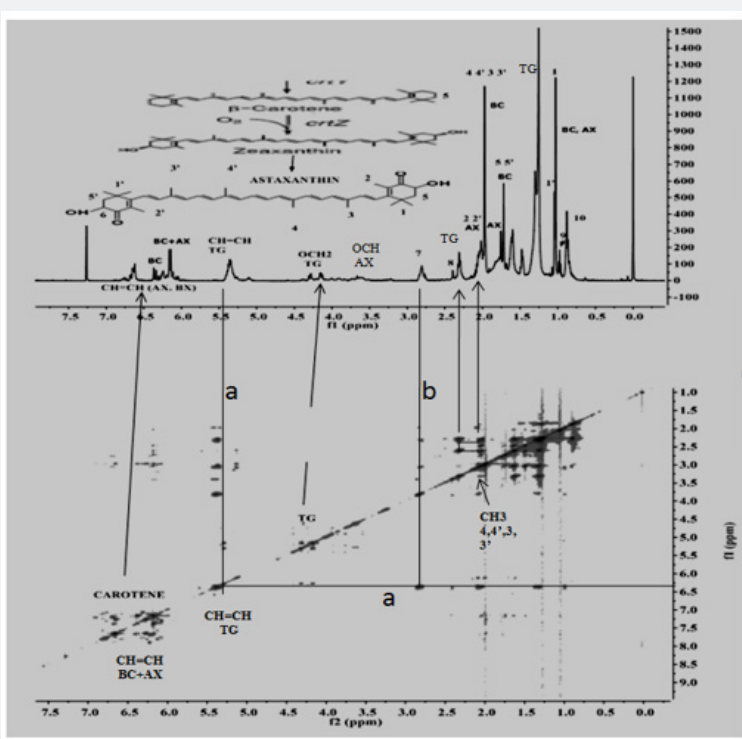

Figure 4: $2 \mathrm{D} 1 \mathrm{H}$ TOCSY NMR $(500 \mathrm{MHz})$ contour plot of purified $\mathrm{CHCl} 3$ extract of biomass. TG=Tri-glycerides, $B C=\beta-\mathrm{Carotene}$, $A X=a x t a x a n t h i n ; a, a ; b=$ unsaturated protons correlation of $T G$.

\section{Determination of quality parameters of biodiesel}

The purified $\mathrm{CHCl} 3$ extract was converted in to Fatty Acid Methyl Ester (FAME), called biodiesel by the usual $\mathrm{KOH}-\mathrm{MeOH}$ transesterification reaction as described in our previous work $[2,4]$. The determination of quality parameters of a biodiesel such as PUFA content, C18:3 content, and iodine value were carried out by the procedures based on $1 \mathrm{H}$ spectral analyses as described in our previous published work $[2,4,8]$ (Figures $2 \&$ 3 ). The IH NMR spectra of FAMEs as given in the Figure 2 (top spectra) has been compared with the 1H NMR spectrum of PUFA standard given in the Figure 1 for the purpose of comparison and identification of functional groups of FAME, particularly OCH3 of methyl esters appearing at $3.7 \mathrm{ppm}$. The integral intensities (I) corresponding to respective functional groups of unsaturation, $\mathrm{CH}=\mathrm{CH}$ (IUS) for iodine value ( IV), n-3 CH3 for PUFA ( IPF,) and ( $\mathrm{CH}=\mathrm{CH}-\mathrm{CH} 2-) 3$ for $\mathrm{C} 18: 3$ (ILA) taken for the determination of these parameters are also described in the Table 1 . The Iodine value, and PUFA and C18:3 contents determined by NMR methods are $132.6 \mathrm{~g} / 10 \mathrm{~g} \mathrm{I} 2,23.6 \% \mathrm{w} / \mathrm{w}$ and $16.7 \% \mathrm{w} / \mathrm{w}$ respectively. The GC-MS analyses have also determined C18:3 and C22:6 as $15.2 \%$ and $6.1 \% \mathrm{w} / \mathrm{w}$ respectively, which is in the same range as determined by NMR analyses. The higher value of iodine value is due to the presence of C22:6 (5-6\% w/w) as confirmed by both NMR and GC-MS analyses. The C22:6 (DHA) is an essential fatty acid for human consumption. Other FAMEs identified by NMR and GC-MS are C16:0, C16:1, C18:0, C18:1 and C18:2 as given in the section of GC-MS analyses. The concentration of Unsaturated Fatty Acids (UFA) (68.7\% w/w) are higher than saturated (SFA).

\section{Conclusion}

The analytical strategy based on NMR (1D \& 2D) spectroscopic techniques has facilitated the identification of $\beta$-carotene, astaxanthin, triglycerides and their fatty acid profile from a single spectral analysis of solvent extracts without their prior separation. The FAMEs of tri-glycerides have been found to comprise of quite higher amount of PUFAs (C18:3, C22:6) besides usual saturated and unsaturated fatty acids. Both $\beta$ carotene and astaxanthin could easy be distinguished from their characteristic signals though these have the same polyene chain. The appearance of separate and well resolved unsaturated protons signals of fatty acid chain (5.2-6.0 ppm) of tri-glycerides and polyene of carotenes has made it convenient to identify in a complex mixture of solvent extracts. The NMR analyses regarding fatty acid composition of PUFAs (C22:6, C18:3) matches with tose determined by GC-MS. The extraction procedure described for the pre-concentration of $\beta$-carotene and astaxanthin and their subsequent analyses offers a convenient method for their separation from tri-glycerides and their subsequent analyses.

\section{References}

1. Sarpal AS, Costa ICR, Teixeira CMLL, Filocomo D, Candido R, et al. (2016) Investigation of Biodiesel Potential of Biomasses of Microalgaes Chlorella, Spirulina and Tetraselmis by NMR and GC-MS Techniques. Journal of Biotechnology Biomaterial 6(1): 1-15.

2. Kumar R, Bansal V, Patel MB, Sarpal AS (2014) Compositional Analysis of Algal Biomass in a Nuclear Magnetic Resonance (NMR) Tube. JABU 5(3): $36-45$ 
3. Sarpal AS, Silva PRM, Pinto RF, Cunha VS, Daroda RJ, et al. (2014) Biodiesel potential of oleaginous yeast biomass by NMR spectroscopic techniques. Energy Fuels 28(6): 3766-3777.

4. Sarpal AS, Teixeira CMLL, Silva PRM, Lima GM, Silva SR, et al. (2015) Determination of lipid content of oleaginous microalgae biomass by NMR spectroscopic and GC-MS techniques. Anal Bioanal Chem 407(13): 3799-3816.

5. Sarpal AS, Teixeira CMLL, Silva PRM, Monteiro TV, Itacolomy J, et al. (2016) NMR techniques for determination of lipid content in microalgal biomass and their use in monitoring the cultivation with biodiesel potential. Appl Microbiol Biotechnol 100(5): 2472-2485.

6. Williams PJ Le B, Lauren L M L (2010) Microalgae as biodiesel \& biomass feedstocks: Review \& analysis of the biochemistry, energetics \& economics. Energy Environmental Science 3(5): 554-590.

7. Sarpal AS, Silva PRM, Silva SR, Monteiro TV, Itacolomy J, et al. (2015) A Direct Method for the determination of iodine value of biodiesel by Quantitative Nuclear Magnetic Resonance (q1H-NMR) Spectroscopy. Energy Fuels 29(12): 7956-7968.

8. Emeish S (2012) Production of Natural $\beta$-Carotene from Dunaliella Living in the Dead Sea. Jordan Journal of Earth and Environmental Sciences (JEES) 4(2): 23-27.

9. Haiying Tang, Nadia Abunasser, MED Garcia, Meng Chen, KY Simon Ng, et al. (2011) Potential of microalgae oil from Dunaliella tertiolecta as a feedstock for biodiesel. Applied Energy 88(10): 3324-3330.

10. Hounslow E (2010) Optimum salinity conditions for producing lipids from Dunaliella salina for biofuels production, Energy Futures Doctoral Training Centre for Interdisciplinary Energy Research. Mini-project report 5: $13-21$

11. Christaki E, Bonos E, Giannenas I, Florou-Paneri P (2013) Functional properties of carotenoids originating from algae. J Sci Food Agri 93(1): 5-11.

12. Ahmad AL, Mat Yasin NH, Derek CJC, Lim JK (2011) Microalgae as a sustainable energy source for biodiesel production: A review. Renewable and Sustainable Energy Reviews 15(1): 584-593.

13. Serive B, Nicolau E, BeÂrard JB, Kaas R, Pasquet V, et al. (2017) Community analysis of pigment patterns from 37 microalgae strains reveals new carotenoids and porphyrins characteristic of distinct strains and taxonomic groups. PLOS One 12(2): e0171872.

14. Sayed Mehdi Hashemi Sohi, Anoosh Eghdami (2014) Biodiesel production using marine microalgae Dunalialla salina. J Bio \& Env Sci 4(2): 177-182.

15. Mata TM, Martins AA, Caetano NS (2010) Microalgae for biodiesel production and other applications: A review. Renewable and Sustainable Energy Reviews 14(1): 217-232.

16. Volkman JK, Jeffrey SW, Nichols PD, Rogers GI, Garland CD (1989) Fatty acid and lipid composition of 10 species of microalgae used in mariculture. Journal of Experimental Marine Biology and Ecology 128(3): 219-240.

17. Kim W, Park JM, Gim GH, Jeong S, Kang CM, et al. (2012) Optimization of culture conditions and comparison of biomass productivity of three green algae. Bioprocess and Biosyst Eng 35(1-2): 19-27.
18. Sharma KK, Schuhmann H, Schenk PM (2012) High Lipid Induction in Microalgae for Biodiesel Production. Energies 5(5): 1532-1553.

19. Meher LC, Sagar VD, Naik SN (2004) Technical aspects of biodiesel production by transesterification-a review. Renewable and Sustainable Energy Reviews. 10(3): 248-268.

20. Al-lwayzy SH, Yusaf T, Al-Juboori, RA (2014) Biofuels from the Fresh Water Microalgae Chlorella vulgaris (FWM-CV) for Diesel Engines. Energies 7(3): 1829-1851.

21.Zhao C, Brück T, Lercher, JA (2013) Catalytic deoxygenation of microalgae oil to green hydrocarbons. Green Chemistry 15: 1720-1739.

22. Mata TM, Almeida R, Caetano NS (2013) Effect of the culture nutrients on the biomass and lipid productivities of microalgae Dunaliella tertiolecta. Chemical Engineering Transaction 32: 973-978.

23. Takagi M, Karseno YY (2006) Effect of salt concentration on intracellular accumulation of lipids and triacylglycerides in marine microalgae Dunaliella cells. J Biosc and Bioeng 101(3): 223-226.

24. Holtin K, Kuehnle M, Rehbein J, Schuler P, Nicholson G, Albert K (2009) Determination of astaxanthin and astaxanthin esters in the microalgae Haematococcus pluvialis by LC-(APCI)MS and characterization of predominant carotenoid isomers by NMR spectroscopy. Anal Bioanal Chem 395(6): 1613-22.

25. Breithaupt DE (2004) Identification and quantification of astaxanthin esters in shrimp (Pandalus borealis) and in a microalga (Haematococcus pluvialis) by liquid chromatography-mass spectrometry using negative ion atmospheric pressure chemical ionization. Agric Food Chem. 52(12): 3870-3875.

26. Ambati RR, Moi PS, Ravi S, Aswathanarayana RC (2014) Astaxanthin: Sources, Extraction, Stability, Biological Activities and Its Commercial Applications- A Review. Mar Drugs 12(1): 128-152.

27. Higuera-Ciapara I, Félix-Valenzuela L, Goycoolea, FM (2006) Astaxanthin: A Review of its Chemistry and Applications Crit Rev Food Sci Nutrition. 46(2): 185-196.

28. Lu M, Zhang Y, Zhao C, Zhou P, Yu L (2010) Analysis and Identifi cation of Astaxanthin and its Carotenoid Precursors from Xanthophyllomyces dendrorhous by High-Performance Liquid chromatography. Z Naturforsch C 65(7-8): 489-494.

29. Shengzhao Dong, Yi Huang, Rui Zhang, Shihui Wang, Yun Liu (2014) Four Different Methods Comparison for Extraction of Astaxanthin from Green Alga Haematococcus pluvialis. The Scientific World Journal: 1-7.

30. Burri BJ (2017) $\beta$-carotene and Human Health: a Review of current research. Nutrition Research 17(3): 547-580.

31. Hariram V, John J G, Seralathan S (2017) Spectrometric analysis of algal biodiesel as a fuel derived through base-catalysed transesterification, through base-catalysed transesterification, International Journal of Ambient Energy.

32. Sarpal AS Brajendra, K Sharma, John Scott, Ravinder Kumar, Vatsala Sugmaran, et al. (2016) Compositional Analyses of Oil Extracts of microalgae Biomasses by NMR and Chromatographic Techniques. J Anal Bioanal Sep Tech 1(1): 17-41. 
This work is licensed under Creative Commons Attribution 4.0 Licens

DOI:10.19080/AIBM.2018.11.555812

\section{Your next submission with Juniper Publishers} will reach you the below assets

- Quality Editorial service

- Swift Peer Review

- Reprints availability

- E-prints Service

- Manuscript Podcast for convenient understanding

- Global attainment for your research

- Manuscript accessibility in different formats

( Pdf, E-pub, Full Text, Audio)

- Unceasing customer service

Track the below URL for one-step submission https://juniperpublishers.com/online-submission.php 